\title{
Eficacia y Tolerancia de la Ciprofloxacina en la Endometritis Post Parto
}

\author{
Dres.: *Carlos A. Quintero J., **Hernando Navarro V., ***María Eugenia González, \\ $* * * *$ Rafael A. Camacho M.
}

\section{INTRODUCGION}

La Endometritis Postparto es de las infecciones nosocomiales que más ocurre y se presenta con una frecuencia de 1 a $4 \%$. Es común en nuestro medio manejar pacientes con factores de riesgo, que predisponen para presentar infección materna y que aumentan la susceptibilidad a las infecciones. Factores como condiciones de nutrición y vida, anemia y hechos tan importantes como la frecuencia alta de ruptura prematura de membranas, $(22 \%$ de nuestras pacientes), el uso frecuente de monitoría intraparto (casos de riesgo obstétrico) y el alto porcentaje de intervenciones como la operación cesárea, $(27 \%)$ hacen que se aumente el riesgo de endometritis postparto. También debe tenerse en cuenta que en un $80 \%$ nuestras pacientes son remitidas de la periferia de la ciudad y muchas de ellas han estado sometidas a trabajos de parto prolongados,

* Profesor Titular. Jefe Departamento de Obstetricia y Ginecología, Facultad de Salud. Universidad del Valle.

** Profesor Asociado. Jefe Servicio Sépticas. Departamento de Obstetricia y Ginecología. Facultad de Salud. Universidad del Valle.

*** Profesor Asistente. Sección Bacteriología y Laboratorio Clínico. Facultad de Salud. Universidad del Valle.

**** Residente de Segundo Año. Departamento de Obstetricia y Ginecología. Facultad de Salud. Universidad del Valle. manipulación, etc. y el $50 \%$ de ellas no han tenido ningún control prenatal. $(7,3,4,5)$.

Cuando se presenta la endometritis postparto, tradicionalmente se ha utilizado un tratamiento consistente en la combinación de penicilina y un aminoglucósido, según criterios basados en que las bacterias más frecuentes que causan el problema pueden responder a este régimen terapéutico y además, teniendo en cuenta la fácil adquisición de estos productos y su costo. Sin embargo, los conocimientos recientes demuestran que sólo un 30-40\% de las infecciones pueden responder a esta terapia, ya que la infección puerperal no se debe a un solo germen sino a una combinación de ellos, posiblemente aerobios y anaerobios.

Por otro lado, el uso de drogas tales como los aminoglucósidos, requieren administración parenteral lo que incluye un factor que puede ser causa de no cumplimiento por el paciente o tener mayor morbilidad cuando el tratamiento se hace ambulatorio $(6-7)$.

\section{Objetivo}

E1 objetivo de este trabajo consiste en usar un derivado exoquinolínico de amplio espectro (Ciprofloxacina o BAY 9867), (1) de administración oral, comprobar su eficacia y tolerancia en pacientes ambulatorios con Dx. de endometritis postparto o post cesárea y compararlo con el tratamiento tradicional usando la combinación de penicilina y un aminoglucósido. 


\section{MATERIALES Y METODOS}

$\mathrm{Al}$ estudio ingresaron 40 pacientes, las cuales se dividieron en dos grupos. Un grupo recibió Penicilina P Potásica, en tabletas de 500 mg. $(800.000$ U) cada 6 horas y $160 \mathrm{mg}$. de gentamicina repartidas en 2 dosis IM al día durante 7 días.

El otro grupo recibió Ciprofloxacina, 1 tableta de $500 \mathrm{mg}$. cada 12 horas durante 7 días.

Las pacientes fueron seleccionadas según una lista de randomización previamente establecida.

\section{Criterios de Inclusión:}

a. Las pacientes debían conocer el trabajo y aceptarlo con el compromiso de asistir a los controles y recibir adecuadamente la droga. Además tener las siguientes características:

- Mayor de 18 años.

- Con infección endometrial clínicamente evaluada postparto o postcesárea, que no requería hospitalización (sin cuadro abdominal agudo o absceso pélvico).

- Compromiso de hacer el tratamiento ambulatorio y regresar al 7o. día o antes si había algún cambio.

- Cultivo de cavidad positivo con más de $10^{5}$ colonias.

\section{Criterios de Exclusión:}

- Reacción alérgica positiva en la prueba subcutánea a la Ciprofloxacina o a la Penicilina.

- Que el estado clínico de la paciente no permitiera manejo ambulatorio.

- Que no necesitara otro antibiótico concomitante al estudio.

- Creatinina sérica mayor de $1.5 \mathrm{mg}$. o depuración (clearance) menor de $70 \mathrm{ml} . / \mathrm{min}$.

- Que el germen causante presentara durante la época del trabajo resistencia.
Las pacientes en el día de su ingreso al programa, además de la prueba de sensibilidad antibiótica, se les practicó un cuadro hemático completo y química completa y se les tomó muestra de cavidad endometrial para estudio bacteriológico (aerobios y anaerobios) y un parcial de orina.

La técnica utilizada fue la toma de muestra de cavidad uterina con escobillón y equipo de transporte cerrado, previa asepsia y antiasepsia cérvicovaginal con substancias yodadas. La toma fue hecha por la misma persona en todos los casos. Para asegurar que la toma de la muestra no presentaba contaminación de vagina y cervix, se hizo un chequeo tomando 9 muestras extras, previa asepsia con solución yodada, y toma de las mismas antes de cumplir 3 minutos de la aplicación antisép tica. El análisis de estas muestras demostró que los cultivos fueron negativos. En cambio los tomados antes de la limpieza demostraron contenido de flora normal.

Teniendo en cuenta el estado clínico de la paciente y la dificultad de regreso al hospital a las 48 horas, se les inició inmediatamente el tratamiento. $\mathrm{Si}$ el estado general de la paciente a las 48 horas era igual, o había síntomas de empeoramiento, a la paciente se le indicaba que regresara al hospital.

Todas asistían al control el día 7o. del tratamiento, día en el cual se les hacía un control clínico y se les tomaba de nuevo los exámenes de laboratorio de control.

\section{Métodos de Evaluación:}

Se efectuaron los siguientes procedimientos y controles previos al tratamiento: toda paciente tuvo una historia clínica y se les llenó una forma previamente suministrada por Bayer de Colombia, donde se consignaba los datos del interrogatorio y el examen físico. El examinador fue el mismo tanto al ingreso como en los controles.

Se realizaron las siguientes determinaciones analíticas:

Hemoglobina

Hematocrito

Recuento de glóbulos rojos y blancos

Fórmula leucocitaria

Sedimentación

Bilirrubinas

Fosfatasa alcalina

Acido úrico 
Fósforo inorgánico

Glicemia

Alanina amino transferasa sérica

Aspartasa amino transferasa sérica

Análisis de orina completo.

Pruebas de Sensibilidad:

A todas las pacientes se les hizo pruebas de. sensibilidad a las muestras tomadas de cavidad antes y después del tratamiento según la técnica que se describirá más adelante.

Si después del tratamiento con el fármaco el paciente requería tratamiento adicional, se practicafon cultivos y nuevas pruebas analíticas antes de iniciar un nuevo tratamiento.

Se contrató una trabajadora social, que se encargó de visitar a las pacientes, asegurándose de que estaban haciendo el tratamiento y que asistieran al control y vigilaba mediante interrogatorio las reacciones anormales, anotando debidamente en el formulario, así como si habían interrumpido el tratamiento temporalmente o habían tenido alguna reducción en la dosificación.

Los criterios de evaluación clínica y evolución fueron los siguientes:

Resolución: cuando el resultado clínico era excelente; Mejoría cuando persistía algunos de los signos o síntomas;

Fracaso cuando no había ninguna mejoría; e Indeterminado cuando no se podía hacer ningún tipo de evaluación por cualquier causa.

\section{Análisis y Tratamiento de los Datos:}

Los datos fueron procesados por BAYER AG y sometidos a análisis estadísticos de acuerdo a: a) Randomización; b) Pruebas de significancia estadística.

\section{Análisis Bacteriológico:}

Al recibir las muestras en el laboratorio se les aplicó el procedimiento diseñado por la Dra. Vera Sutter (2) que consiste en: preparar un frotis coloreado por Gram y llevar la muestra a un cooked meat medium pre-reducido, seguido de incubación por 48 horas, para inocular posteriormente en:
1. Agar sangre (con base de Brucella, Columbia, ó Shacedler).

2. Agar sangre lakeada + Kanamicina + Vancominicina + Vitk, Hemina (KVLB) ó en su ausencia se reemplazó por un agar sangre $+\mathrm{GN}$ $($ OxoidR $)$.

En las cajas examinadas bajo una lente, se determinaron los tipos de colonias diferentes que había, se hizo de nuevo un Gram de cada una de ellas y se les repicó también en agar sangre por duplicado, uno a la atmósfera de $\mathrm{CO}_{2}$ y otro a anaerobiosis. La anterior constituyó la prueba de aerotolerancia.

A las bacterias anaerobias estrictas y aquellas aerotolerantes que por su morfología en Gram sugieren ser anaerobios, se les hizo Minitek (9).

La identificación total se completó con: morfología de las colonias buscando:

- Pigmentos

- Hemólisis

- Fluorescencia

- Reactividad al Indol.

Para la concentración inhibitoria mínima se resuspendieron las colonias ya purificada e identificada en $3 \mathrm{cc}$. de caldo de tioglicolato o de tripticasa suplementado con Hemina, se incubó por 48 horas en anaerobiosis, se ajustó la turbidez a 1:200 y se corrió el ensayo para determinar como concentración inhibitoria mínima, el último tubo de transparencia de la serie de diluciones.

El mismo inoculo diluído y ajustado 1:200 fue utilizado para la prueba de difusión del disco en el agar.

\section{RESULTADOS}

\section{Discusión y Comentarios:}

1. Se estudió la respuesta clínica en 20 pacientes que recibieron Ciprofloxacina y 20 pacientes tratadas con penicilina más gentamicina. Los grupos mostraron homogeneidad en sus características, así 
como en el grado de infección (Tabla 1). No se encontraron diferencias estadísticamente significativas en los antecedentes gineco-obstétricos ni en los factores de riesgo revisados (Tablas 2 y 3 ). El seguimiento de las pacientes fue adecuado en los 2 grupos, terminando el estudio la casi totalidad de las pacientes (Tabla 4 ).

TABLA 1

CARACTERISTICAS GENERALES (MEDIAS + S.D.)

\begin{tabular}{|c|c|c|c|c|}
\hline \multirow[b]{2}{*}{ No. de pacientes } & \multicolumn{2}{|c|}{$\begin{array}{l}\text { Ciprofloxa- } \\
\text { cina }\end{array}$} & \multicolumn{2}{|c|}{$\begin{array}{l}\text { Penicilina } \\
\text { Gentamicina }\end{array}$} \\
\hline & 20 & $(100 \%)$ & 20 & $(100 \%)$ \\
\hline Edad (años) & $23 \pm$ & 4 & $21 \pm$ & 4 \\
\hline Talla (cm.) & $158 \pm$ & 3 & $158 \pm$ & 5 \\
\hline Peso (kg.) & $56 \pm$ & 7 & $57 \pm$ & 2 \\
\hline \multicolumn{5}{|l|}{ Raza: } \\
\hline Blanca & 9 & $(45 \%)$ & 8 & $(40 \%)$ \\
\hline Negra & 4 & ( $20 \%)$ & 2 & $(10 \%)$ \\
\hline Mestiza & 7 & $(35 \%)$ & 10 & $(50 \%)$ \\
\hline \multicolumn{5}{|l|}{ Estado Civil: } \\
\hline Soltera & 10 & $(50 \%)$ & 7 & $(35 \%)$ \\
\hline Casada & 1 & $(5 \%)$ & 1 & $(5 \%)$ \\
\hline Otro & 9 & $(45 \%)$ & 12 & $(60 \%)$ \\
\hline \multicolumn{5}{|l|}{$\begin{array}{l}\text { Cuadro Clínico } \\
\text { (Endometritis): }\end{array}$} \\
\hline Leve & 17 & $(85 \%)$ & 16 & $80 \%)$ \\
\hline Moderado & 3 & $(15 \%)$ & 4 & $(20 \%)$ \\
\hline
\end{tabular}

2. Los gérmenes obtenidos de cavidad uterina fueron similares en los 2 grupos, predominando los anaerobios y entre éstos los bacteroides; (19 pacientes), seguido de peptococcus (6 pacientes).

La erradicación del germen en el grupo de la Ciprofloxacina fue de $78 \%$ y la persistencia del $22 \%$, en el grupo de penicilina y gentamicina estas cifras fueron del $62 \%$ y $38 \%$ respectivamente, no encontrándose diferencia significativa entre los dos grupos (Tabla 5).

Las tablas 6 y 7 muestran las concentraciones inhibitorias mínimas que se hicieron para los dife- rentes grupos de cepas tanto de anaerobios (Tabla 9 ), como de aerobios (Tabla 10). Se muestra los percentiles $10-50$ y 90 y el rango de la respuesta. Hubo 38 cepas de anaerobios y 11 de aerobios, distribuídos en los diferentes grupos de estudio, tal como fueron presentados previamente.

3. La respuesta clínica evaluada según los parámetros establecidos, mostró resolución de la infección en los 18 casos que terminaron al estudio con Ciprofloxacina (90\%) y para las pacientes que recibieron Penicilina/Genta la resolución fue en 11 $(55 \%)$, siendo estadísticamente significativa esta diferencia entre los 2 resultados. Los 6 casos restantes del grupo de Penicilina/Genta presentaron mejoría $(30 \%$ ) (Tabla 8). En la Tabla 9 se muestran los factores de no resolución del cuadro clínico en este último grupo.

4. La Tabla 10 expresa la evaluación global en la cual se consideran la respuesta clínica y los hallazgos bacteriológicos encontrando como excelente el resultado en $70 \%$ (14 casos) en el grupo que recibió Ciprofloxacina y bueno en el 20\% (4 casos).

TABLA 2

\section{ANTECEDENTES GINECO - OBSTETRICOS}

\begin{tabular}{|lllll|}
\hline & \multicolumn{2}{c|}{$\begin{array}{l}\text { Ciprofloxa- } \\
\text { cina }\end{array}$} & $\begin{array}{l}\text { Penicilina }+ \\
\text { Gentamicina }\end{array}$ \\
\hline $\begin{array}{l}\text { Menarquia } \\
\text { (media S.D.) }\end{array}$ & $13,7 \pm 1.8$ & $13.8 \pm 2.3$ \\
Ciclo (días): & & & & \\
$30 \times 3$ & 8 & $(40 \%)$ & 5 & $(25 \%)$ \\
$30 \times 4$ & 3 & $(15 \%)$ & 4 & $(20 \%)$ \\
$30 \times 5$ & 6 & $(30 \%)$ & 8 & $(40 \%)$ \\
$30 \times 6$ & 2 & $(10 \%)$ & & $(5 \%)$ \\
$35 \times 7$ & 1 & $(5 \%)$ & 1 & $(10 \%)$ \\
$30 \times 8$ & & & 2 & $(10 \%)$ \\
Paridad (media): & & & & \\
$\begin{array}{l}\text { Gestación } \\
\text { Parto }\end{array}$ & 2.3 & & 2.5 & \\
$\begin{array}{l}\text { Aborto } \\
\text { Cesarea }\end{array}$ & 1.5 & & 2 & \\
\hline
\end{tabular}


En el grupo de Penicilina Gentamicina excelente el $25 \%$ ( 5 casos) y bueno el $60 \%$ (12 casos). Estas diferencias también fueron estadísticamente significativas.

5. No se presentaron complicaciones ni fallas terapéuticas en los 2 grupos, siendo muy bien tolerado los antimicrobianos utilizados en este estudio.

TABLA 3

\section{ANTECEDENTES GINECOLOGICOS} PREVIOS AL ESTUDIO

\begin{tabular}{|c|c|c|c|c|c|c|}
\hline & \multicolumn{3}{|c|}{ Ciprofloxacina } & $\begin{array}{l}\text { Per } \\
\text { n }\end{array}$ & cilin & días \\
\hline Parto & 10 & 50 & 7 & 8 & 40 & 7 \\
\hline Cesarea & 10 & 50 & 9 & 12 & 60 & 11 \\
\hline Factores de Riesgo: & & & & & & \\
\hline $\begin{array}{l}\text { Trabajo de parto } \\
\text { prolongado }\end{array}$ & 1 & 5 & & & & \\
\hline $\begin{array}{l}\text { Ruptura prematura } \\
\text { membrana }\end{array}$ & 3 & 15 & & 4 & 20 & \\
\hline $\begin{array}{l}\text { Manipulación } \\
\text { Intraparto }\end{array}$ & 2 & 10 & & 4 & 20 & \\
\hline $\begin{array}{l}\text { Monitoría } \\
\text { electrónica } \\
\text { intraparto }\end{array}$ & 1 & 5 & & & & \\
\hline Otros & 3 & 15 & & 6 & 30 & \\
\hline
\end{tabular}

TABLA 4

PACIENTES QUE TERMINARON EL TRATAMIENTO

\begin{tabular}{|lcccc|}
\hline & \multicolumn{2}{c|}{ Ciprofloxacina } & \multicolumn{2}{c|}{ Penicilina } \\
& n & $\%$ & n & $\%$ \\
\hline $\begin{array}{l}\text { Complementaron } \\
\text { el estudio }\end{array}$ & 18 & 90 & 17 & 85 \\
$\begin{array}{l}\text { Pacientes } \\
\text { perdidos }\end{array}$ & 2 & 10 & 3 & 15 \\
\hline
\end{tabular}

6. Finalmente el estudio nos brindó un aporte importante para nuestro conocimiento pues nos permitió identificar la flora bacteriana, especial- mente de anaerobios, presente en la infección puerperal en los casos leves y moderados. Llamó la atención el bajo número de infección por $\mathrm{E}$. Coli en las pacientes analizadas.

\section{CONCLUSIONES}

Los resultados encontrados en nuestra experiencia nos pueden hacer afirmar que la Ciprofloxacina por vía oral, es uno de los antimicrobianos elegibles para el tratamiento de las infecciones endouterinas postparto o postcesárea en forma ambulatoria, en aquellas pacientes con un cuadro clínico moderado y que no tiene una causa de severidad que justifique su hospitalización.

Además el hecho de su respuesta clínica frente a casos en los cuales se aislaron bacteroides así como su buena tolerancia, hacen que su uso sea adecuado en este tipo de infección gineco-obstétrica tan frecuente en nuestro medio.

\section{RESUMEN}

Se analizaron 40 pacientes con un cuadro clínico de endometritis postparto o postcesárea, en un estudio simple ciego randomizado con el fin de comparar la eficacia y la tolerancia de un oxiquinolínico de amplio espectro (la ciprofloxacina) administrado por vía oral, comparándola con el esquema tradicional de la combinación Penicilina-aminoglucósido (gentamicina).

Se hicieron 2 grupos de 20 pacientes cada uno, que presentaron un grado de infección mediana o moderada y que podían ser manejadas en forma ambulatoria. Se efectuaron cultivos de la cavidad uterina previa asepsia estricta, cérvico vaginal, con solución yodada. La mayoría de los gérmenes obtenidos pertenecieron a los grupos de anaerobios Gram negativos (bacteroides) los cuales se encontraron solos o asociados a gérmenes aeróbicos en su mayoría Gram positivos (estafilococcus epidermides).

Las pacientes se evaluaron al finalizar la terapia de 7 días, encontrando una respuesta mejor y estadísticamente significativa en el grupo que recibió la ciprofloxacina frente al grupo de penicilina y gentamicina, a pesar de que no se encontraron fallas terapéuticas en los 2 grupos. Un hallazgo muy importante fue la respuesta clínica a la ciprofloxacina en aquellos casos en los cuales se aisló gérmenes anaerobios (bacteroides). 


\section{SUMMARY}

40 patients were analized with a clinical table of endometritis postpartum or post-caesarean section, in a simple blind randomized study to compare the efficiency and the tolerance of a carbostyril with wide spectrum (the ciprofloxacine) by oral way, comparing it with the traditional table of the combination Penicillin-aminoglycocid (gentamicine).

There were made 2 groups of 20 patients each, which presented a middle or moderated infection degree, and which could be managed in ambulatorian way. Cultures of the uterine cavity, wtih former strict asepsis, cervicovaginal, with iodated solution were made. The main number of germs obtained were from the group of anaerobes Gram negatives (bacteroids), which were found allone or in association with aerobic germs, mainly Gram positive (estafilococcus epidermides).

The patients were evaluated at the end of the 7 days therapy, finding a better and statistically significant response in the group which received the ciprofloxacine comparing with the group of penicillin and gentamicine, though there were not found therapeutical fails in the wo groups.

A very important finding was the clinical response to the ciprofloxacine in these cases in which the anaerobic germs were isolated (bacteroids).

TABLA 5

RESPUESTA BACTERIOLOGICA

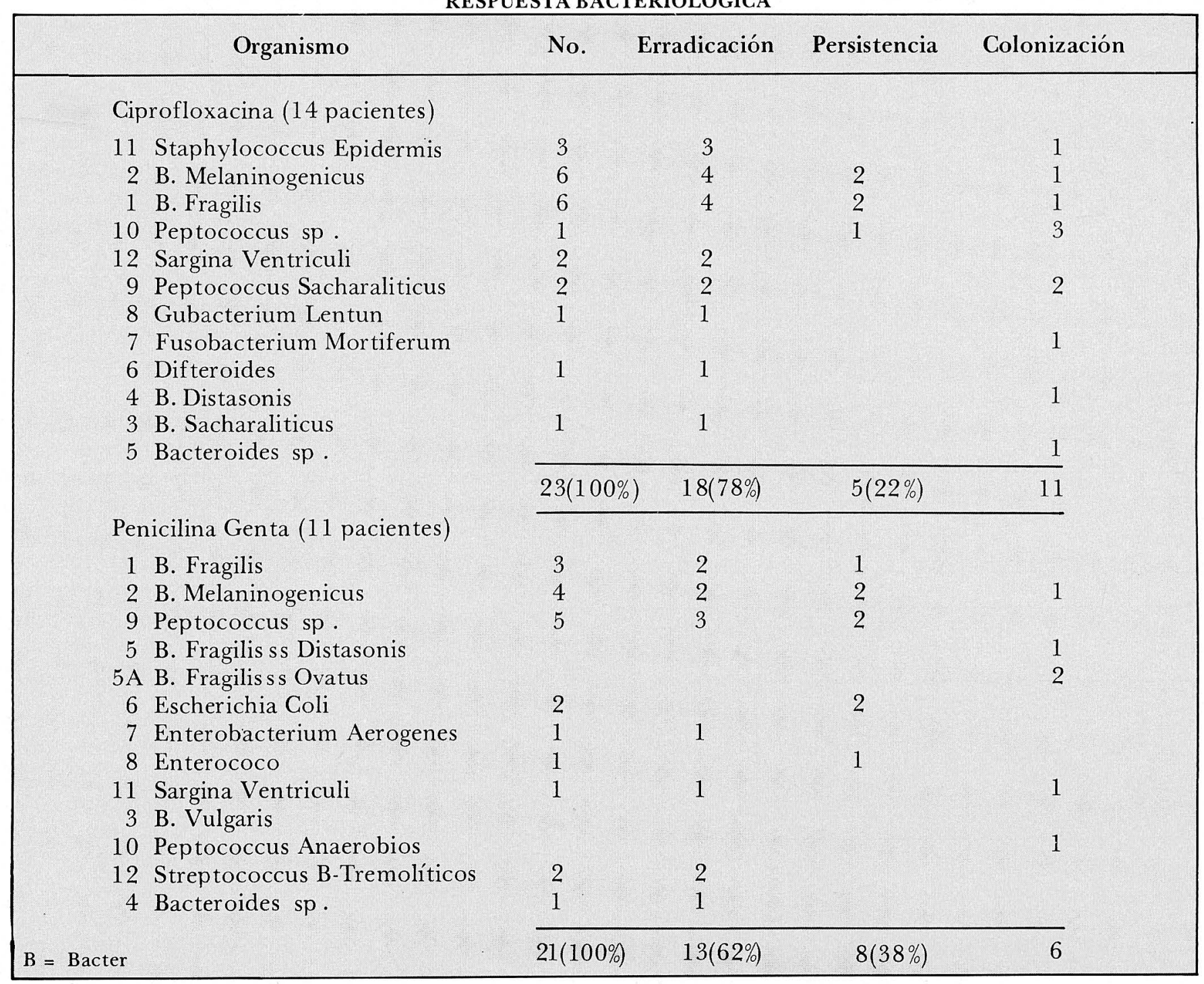


TABLA 6

CONCENTRACIONES INHIBITORIAS MINIMAS EN GERMENES ANAEROBICOS

\begin{tabular}{|lcclll|}
\hline & $\begin{array}{l}\text { No.de } \\
\text { Cepas }\end{array}$ & $\begin{array}{l}\text { CIM10 } \\
\mu \mathrm{g} / \mathrm{ml} .\end{array}$ & $\begin{array}{l}\text { CIM } 50 \\
\mu \mathrm{g} / \mathrm{ml}\end{array}$ & $\begin{array}{l}\text { CIM90 } \\
\mu \mathrm{g} / \mathrm{ml} .\end{array}$ & $\begin{array}{l}\text { Rango } \\
\mu \mathrm{g} / \mathrm{ml} .\end{array}$ \\
\hline $\begin{array}{l}\text { Bacteroides sp } \\
\text { Fusobacterium }\end{array}$ & 22 & 0.03 & 0.125 & 0.5 & $0.03-0.5$ \\
Mortiferum & 1 & 2 & 2 & 2 & 2 \\
Peptococcus sp & 11 & 0.06 & 0.25 & 1 & $0.03-2$ \\
Peptostreptococcus sp & 2 & 0.06 & 0.06 & 0.125 & $0.06-0.25$ \\
Eubacterium sp & 1 & 0.5 & 0.5 & 0.5 & 0.5 \\
Propionibacterium sp & 1 & 0.06 & 0.06 & 0.06 & 0.06 \\
Total de Cepas & 38 & - & - & - & - \\
\hline
\end{tabular}

TABLA 7

CONCENTRACIONES INHIBITORIAS MINIMAS EN GERMENES AEROBICOS

\begin{tabular}{|c|c|c|c|c|c|}
\hline & $\begin{array}{l}\text { No. de } \\
\text { Cepas }\end{array}$ & $\begin{array}{l}\mathrm{CIM}_{10} \\
\mu \mathrm{g} / \mathrm{ml}\end{array}$ & $\begin{array}{l}\mathrm{CIM} 50 \\
\mu \mathrm{g} / \mathrm{ml} .\end{array}$ & $\begin{array}{l}\mathrm{CIM} 90 \\
\mu \mathrm{g} / \mathrm{ml} .\end{array}$ & $\begin{array}{l}\text { Rango } \\
\mu \mathrm{g} / \mathrm{ml} \text {. }\end{array}$ \\
\hline E. Coli & 3 & 0.06 & 0.06 & 0.125 & $0.06-0.125$ \\
\hline Enterobacteraerógenes & 1 & 0.125 & 0.125 & 0.125 & 0.125 \\
\hline $\begin{array}{l}\text { Streptococcus Beta } \\
\text { Haemolyticus Grupo A }\end{array}$ & 2 & 0.06 & 0.06 & 0.06 & 0.06 \\
\hline $\begin{array}{l}\text { Streptococcus Grupo D } \\
\text { (Enterococcus) }\end{array}$ & 2 & 0.25 & 0.5 & 1 & $0.25-1$ \\
\hline $\begin{array}{l}\text { Staphilococcus } \\
\text { Epidermis }\end{array}$ & 3 & 0.25 & 0.25 & 0.5 & $0.25-0.5$ \\
\hline Total de Cepas & 11 & - & - & - & - \\
\hline
\end{tabular}

Concent. Inh. Mínimas de Ciprofloxacina.

Gérmenes Anaeróhicos.

TABLA 8

EVALUACION DE LA RESPUESTA CLINICA

\begin{tabular}{|lcc|}
\hline & Ciprofloxacina & Penicilina + Genta \\
\hline Resolución & $18(90 \%)$ & $11(55 \%)$ \\
Mejoría & & $6(30 \%)$ \\
\hline
\end{tabular}

$* \mathrm{p}<0.01$

TABLA 9

FACTORES DE NO RESOLUCION

\begin{tabular}{|lc|}
\hline & Penicilina + Gentamicina \\
\hline Involución Uterina & $4(45 \%)$ \\
Sensibilidad Uterina & $3(33 \%)$ \\
Sensibilidad Anexos & $1(11 \%)$ \\
Presencia Masas & $1(11 \%)$ \\
& $9(100 \%)$ \\
Total: & \\
\hline
\end{tabular}

TABLA 10

EVALUACION GLOBAL

\begin{tabular}{|lrc|}
\hline & Ciprofloxacina & Penicilina + Genta \\
\hline Excelente & $14(70 \%)$ & $5(25 \%)^{*}$ \\
Bueno & $4(20 \%)$ & $12(60 \%)^{*}$ \\
\hline
\end{tabular}

${ }^{*} \mathrm{p}<0.01$

\section{BIBLIOGRAFIA}

1. BALL, A.P.: Overview of Clinical Experience with Ciprofloxacine Microbiology and Pharmacokinesis. Current Topics in Infections and Clinical Microbiology. Vol. 1: 1986.

2. HOLDERMAN, L.V.; CATO, E.P., and W.E.C.: Moore (ed.) 1977 Anaerobic Laboratory Manual, 4th Ed. Virginia Polytechnic and State University, Blackbury.

3. LARSEN, J.W.: Intrauterine Infection on an Obstetric Service. Obstetrics and Gynecology 43: 838, 1974.

4. LARSEN, J.W.: Bacterial Growth inhibition by amniotic fluid. Am. J. Obstetrics and Gynecology. 119: 492, 1974.

5. LEDGER, W.J.: Puerperal Endometritis in Endemic and Epidemic Hospital Infections 395 - 407, 1978.

6. LEDGER, W.J.: Operative care of infections in Obstetrics and Gynecology. J. Reprod. Med. 13: 128, 1974.

7. LEDGER, W.J.: The group A beta-hemolytic streptococcus. Obstetrics and Gynecology 39: 474, 1972.

8. PAUL, R.H., and HON, E.H.: Clinical Fetal monitoring v. Effect on Perinatal outcome. Am.J. Obstet. Gynecol. 118: 529, 1974.

9. SUTTER, V.L., VARGO, V.L. and FINEGOLD, S.M.: Wadsworth Anaerobic Bacteriology Manual. The Reagents of the University of California, Los Angeles. 